\title{
Impactos da Precarização do Trabalho na Segurança Alimentar e Nutricional: contribuições para o debate sobre saúde e alimentação de trabalhadores terceirizados em Unidades de Alimentação e Nutrição
}

\author{
Ariana de Oliveira Tavares ${ }^{1}$, Aldo Pacheco Ferreira ${ }^{2}$ e Maria de Fátima Ramos Moreira ${ }^{3}$
}

No Brasil, a garantia da Segurança Alimentar e Nutricional (SAN) ainda é um desafio, sobretudo para grupos populacionais mais vulneráveis, dentre os quais, os trabalhadores com rendimentos até cinco salários mínimos. Mudanças no mundo do trabalho, desde os anos 90 , alinhadas à precarização do trabalho, com destaque para jornadas laborais flexíveis e baixos salários, desafiam a promoção da saúde dos trabalhadores, como, por exemplo, assegurar uma alimentação saudável e adequada. Assim, objetivou-se analisar a relação entre processo de trabalho e SAN de trabalhadores terceirizados em uma Unidade de Alimentação e Nutrição (UAN). Foi realizado um estudo qualitativo em UAN de uma Instituição Pública Federal de Ensino Superior, onde a observação participante e a entrevista semiestruturada foram empregadas para compreender a tríade trabalho, saúde e alimentação. A organização da produção de refeições na UAN apontou para a intensificação do ritmo de trabalho; para fragmentação do coletivo de trabalhadores; e para prejuízos à saúde dos trabalhadores de ordem física e psíquica. Ficou sinalizado que, na atualidade, no contexto de precarização no mundo do trabalho, as correlações de força desfavoráveis à classe trabalhadora submetem os trabalhadores a uma carga de doenças progressiva e a instabilidade na garantia do Direito Humano à Alimentação Adequada.

Palavras-chave: segurança alimentar e nutricional, saúde do trabalhador, serviços terceirizados.

\section{Impacts of work precarization on food and nutrition security: contributions to the debate on health and nutrition of outsourced workers in Food and Nutrition Units}

In Brazil, the guarantee of Food and Nutrition Security (SAN) is still a challenge, especially for the most vulnerable population groups, among them, workers with incomes up to five minimum wages. Changes in the world of work since the 1990s, in line with the precariousness of work, especially flexible working hours and low wages, challenge the promotion of workers' health, such as ensuring a healthy and adequate diet. Thus, the objective was to analyze the relationship between work process and SAN of outsourced workers in a Food and Nutrition Unit (FNU). A qualitative study was carried out at FNU of a Federal Public Institution of Higher Education, where participant observation and

\footnotetext{
${ }^{1}$ Nutricionista. Mestre em Saúde Pública. Restaurante Universitário, Universidade Federal Fluminense. E-mail: anaira.ot@gmail.com

2 Docente do Programa de Pós-Graduação em Saúde Pública. Escola Nacional de Saúde Pública Sergio Arouca, Fiocruz. Endereço para correspondência: Avenida Brasil no 4.036, sala 905, Manguinhos, Rio de Janeiro, RJ CEP: 21.041-361. Telefone: (21) 3882-9222. E-mail: aldopachecoferreira@gmail.com

${ }^{3}$ Docente do Programa de Pós-Graduação em Saúde Pública e Meio Ambiente. Escola Nacional de Saúde Pública Sergio Arouca, Fiocruz. E-mail: fmoreira@ensp.fiocruz.br
} 
semi-structured interview were used to understand the triad of work, health and food. The organization of food production at FNU pointed to the intensification of workplace; for fragmentation of the collective workers; and for damages to the worker's health of physical and psychic order. It was pointed out that currently, in the context of precariousness in the world of work, the correlations of strength unfavourable to the working class subject the workers to a load of progressive diseases and the instability in guaranteeing the Human Right to Adequate Food.

Keywords: food and nutrition security, occupational health, outsourced services.

\section{INTRODUÇÃO}

Garantir alimentação aos povos é garantir a própria existência humana. Apesar dessa essencialidade, historicamente, a alimentação não fora distribuída e acessada igualmente entre e dentro dos povos. Isso significa dizer, que embora o trabalho humano, entendido como transformação da natureza, tenha permitido produzir alimentos suficientes para atender às necessidades de aproximadamente 7 bilhões de pessoas ${ }^{[1]}$, ainda persistem 805 milhões de pessoas famintas no mundo, até 2 bilhões de pessoas, sofrendo de deficiência de micronutrientes (vitaminas e minerais) ou "fome oculta"[2] e, conforme relatório da Global Health Burden, vinculada à Organização Mundial de Saúde, em torno de 3 milhões de óbitos por obesidade mórbida em 2010[3].

Nesse contexto, mais que garantir a alimentação como sustento à vida, torna-se imperativo a garantia de uma alimentação de qualidade para todos, capaz de promover e preservar a saúde dos povos. Dentro dessa perspectiva, a alimentação precisa ser compreendida a luz da Segurança Alimentar e Nutricional (SAN), fortalecendo a concepção da alimentação como direito humano inalienável.

No Brasil, desde os anos 2000, sobretudo após a promulgação da lei 11.349 de $20066^{[4]}$, vigora um compromisso estatal em assegurar a SAN em território nacional, ou ainda, garantir que todo brasileiro tenha direito a uma alimentação saudável, acessível, com qualidade, em quantidade suficiente, de forma estável, baseada em práticas alimentares promotoras de saúde, sem comprometer outras necessidades básicas, respeitando as singularidades culturais de cada região, sendo social e economicamente sustentáveis.

A SAN ao incorporar a ótica de direito humano, ou mais precisamente do Direito Humano a
Alimentação Adequada, compõe-se de quatro dimensões inter-relacionadas: disponibilidade, acesso, utilização e estabilidade. Tais dimensões colocam que a alimentação deve estar disponível direta (pela agricultura e/ou pecuária) ou indiretamente (em mercados locais ou por cestas básicas de alimentos); acessível econômica e fisicamente em todas as fases da vida; ser adequada quantitativamente e qualitativamente; e satisfatoriamente utilizada pelo organismo humano, que para tanta demanda das pessoas acesso a bens e serviços de saúde, bem como a conhecimentos sobre alimentação e nutrição. Por fim, os alimentos disponíveis, adequados e acessíveis devem ser fornecidos de forma permanente e regular durante todo o tempo, assegurando assim, o atributo da estabilidade[5,6].

Nos últimos 10 anos, o Brasil apresentou avanços em relação a SAN. Em 2014, nosso país deixou de compor o mapa mundial da fome, devido à redução considerável no número de brasileiros em situação de subalimentação, desnutrição e fome. Entretanto, no período de 2004 a 2014, dados revelaram que o número de brasileiros mortos por complicações associadas diretamente à obesidade, mais que dobrou, sendo a quarta causa de morte no país entre as doenças endócrinas, nutricionais e metabólicas []].

Esse panorama nutricional aponta que os problemas de saúde relacionados à ingestão de uma dieta qualitativamente inadequada são igualmente graves aos problemas decorrentes da falta absoluta de acesso aos alimentos ${ }^{[8]}$. Esse quadro atinge de forma mais perversa grupos populacionais vulneráveis. Frente a isso, a Política Nacional de Segurança Alimentar e Nutricional, instituída pelo decreto 7.272/2010, pautou a promoção do acesso universal à alimentação adequada e saudável com prioridade para as famílias e pessoas em Insegurança Alimentar e Nutricional. E determinou para o Plano Nacional de Segurança Alimentar e Nutricional a necessidade de oferta de 
alimentos aos estudantes, trabalhadores e pessoas em situação de vulnerabilidade alimentar[?].

Apesar disso, antes desse compromisso firmado com a promoção da alimentação saudável dos trabalhadores, cabe destacar o Programa de Alimentação do Trabalhador (PAT), um dos mais antigos programas no campo da alimentação e nutrição no Brasil. Datado dos anos 70 e em vigor até os dias atuais, o PAT pode ser considerado um importante instrumento para promoção da SAN dos trabalhadores de baixa renda ${ }^{[10]}$. Entretanto, vários estudos apontaram que as refeições servidas aos trabalhadores sejam por empresas de autogestão ou terceirizadas, estavam nutricionalmente inadequadas, necessitando de medidas para reverter esse quadro. $\mathrm{E}$ ainda, que o setor de serviços, o de maior peso para economia e que concentra 33,2\% dos trabalhadores formais, tem participação no PAT inferior a 50\%[11].

No setor de serviços, um ramo em franco crescimento é o de refeições coletivas. De acordo com dados da Associação Brasileira de Empresas Fornecedoras de Refeições Coletivas (ABERC), o setor forneceu 11 milhões de refeições por dia, movimentando $\mathrm{R} \$ 17,8$ bilhões/ano em 2015[12]. Esse volume de refeições ligou-se intimamente às mudanças na organização do trabalho, levando ao aumento do consumo de refeições fora de casa. De acordo com a Pesquisa de Orçamentos Familiares (POFs) os gastos com alimentação fora do domicílio eram de $24 \%$ do total gasto mensalmente com alimentação, conforme POF 2002-2003, passando a 31\% em 2009[13].

Das 11 milhões de refeições produzidas em 2015, $90 \%$ foram fornecidas por empresas prestadoras de serviço [12]. Isso sugere que um volume expressivo de refeições foi fornecido por empresas que terceirizaram esse serviço. A terceirização consiste em um contrato entre empresas, onde uma (a contratada) presta serviço em outra (a contratante), com objetivo primário de reduzir custos com a força de trabalho.

Essa modalidade de contratação expandiu-se na década de noventa, no contexto da reestruturação produtiva e limitação da intervenção estatal na economia, atingindo inclusive a esfera pública, permitindo a terceirização de "atividades-meio", ou seja, aquelas que não configuravam a missão institucional do órgão público. Assim, serviços de oferta de refeições, limpeza, vigilância, manutenção predial, na educação pública, por exemplo, puderam ser transferidos à iniciativa privada ${ }^{[14,15]}$.

Estudos recentes sobre a temática da terceirização afirmam que os trabalhadores terceirizados experimentam o enfraquecimento das proteções trabalhistas historicamente conquistadas, onde cabe destaque longas jornadas de trabalho e remuneração de 1 a 1,5 salários mínimos, que se revertem, sobremaneira, em ameaças à saúde desses trabalhadores ${ }^{[15,16]}$.

A precarização no mundo do trabalho, portanto, desponta novos desafios para assegurar a SAN de populações sabidamente vulneráveis, como os trabalhadores de baixa renda, sobretudo, pela imposição de dinâmicas de trabalho sacrificantes e mal remuneradas que prejudicam a saúde desses trabalhadores, inclusive, pela dificuldade de acessar e manter uma alimentação saudável e adequada[17].

Desse modo, trabalhadores terceirizados em serviços de alimentação, embora devido à natureza do trabalho, possam acessar alimentos disponíveis durante o cotidiano laboral, o modo de organização do trabalho pode impactar, negativamente, o acesso qualitativo e mesmo quantitativo de alimentos. Ademais, a baixa remuneração inerente ao trabalho terceirizado pode comprometer a adoção de uma alimentação saudável no domicílio, visto a associação positiva entre renda e alimentação saudável[18]. Assim, sempre que o acesso regular e contínuo a uma alimentação saudável for violado/negado, necessariamente, o trabalhador estará em situação de insegurança alimentar e nutricional.

Nesse contexto e diante de poucos dados, na atualidade, que investiguem a relação entre alimentação e saúde dos trabalhadores, onde a categoria "processo de trabalho" seja pesquisada, como apontaram Araújo et al. [19], o presente estudo buscou trazer contribuições para esse debate.

\section{MÉTODOS}

A pesquisa foi realizada no período de junho a dezembro de 2016, no Restaurante Universitário da Universidade Federal Fluminense (RU-UFF), localizado no campus Gragoatá da UFF, em Niterói, Rio de Janeiro, Brasil. Nesta Unidade funcionava a Área de Produção de Refeições (Cozinha Industrial) do 
Restaurante e dois refeitórios destinados à oferta de almoço e jantar para estudantes, docentes e técnicoadministrativos da UFF, trabalhadores terceirizados de empresas prestadoras de serviço para a Universidade, além de visitantes autorizados.

A amostra foi constituída de trabalhadores terceirizados diretamente envolvidos no processo de produção de refeições no RU-UFF, sendo 77 trabalhadores da empresa X e 16 trabalhadores da empresa Y. Desse universo de 93 trabalhadores, aceitaram participar da pesquisa 68 trabalhadores (73,1\%), sendo 59 da empresa X e 9 trabalhadores da empresa Y. Participaram das entrevistas, considerando o critério de saturação para determinação do número de entrevistados, da primeira empresa, 26 trabalhadores e da segunda, 5 trabalhadores, totalizando 31 entrevistados nessa etapa, ou ainda, 33,3\% do universo de pesquisa.

Como instrumento para coleta de dados buscou-se técnicas que pudessem valorizar a fala dos trabalhadores (individual e coletiva), enquanto processo de elaboração, e que possibilitassem identificar a dinâmica do processo de trabalho. Para isso, utilizou-se a observação participante e a entrevista semiestruturada ${ }^{[20]}$.

A observação participante consistiu em momentos de interação entre pesquisador e pesquisado em diferentes etapas do processo de produção de refeições coletivas. A entrevista semiestruturada foi agendada de acordo com a disponibilidade do trabalhador, e realizada em local que possibilitasse sigilo das informações colhidas. O roteiro de entrevista foi composto de 17 perguntas, cuja elaboração preocupouse com grau de indução das questões, linguagem inteligivel e sequência dos questionamentos, em vias de favorecer a aplicação das entrevistas e a fidedignidade das respostas obtidas[21].

Para caracterização do perfil dos pesquisados, buscou-se dados sociodemográficos dos trabalhadores terceirizados, mediante registro em ficha cadastral própria de cada empresa terceirizada e, em casos de ausência desse dado no referido documento, buscou-se acionar o próprio trabalhador para obtenção dessa informação.
Ainda foram consultados materiais oficiais e privativos relacionados aos processos de trabalho na unidade de pesquisa, quais sejam: o Manual de Boas Práticas de Manipulação de Alimentos do Restaurante Universitário da UFF (RU-UFF), versão 2016 e a escala de serviço dos trabalhadores envolvidos na produção de refeições do restaurante em vias de complementar a análise dos dados coletados pelas entrevistas e/ou observação participante.

$\mathrm{Na}$ fase de análise dos dados, os entrevistados foram nomeados pela combinação da letra " $E$ " e de números em escala ordinal de 1 a 31, ou seja, com a identificação "E1"; "E2" e assim sucessivamente em vias de preservar suas identidades. E o material resultante dessa técnica foi dividido nos temas: modo de organização do trabalho, relação saúde e trabalho e relação trabalho e alimentação. Dentro de cada um desses temas, por sua vez, buscou-se apreender a estrutura e a dinâmica dos mesmos pela frequência dos elementos resultantes na análise por cargos, por empresa, por tempo de trabalho e por área/subárea de atuação no RU-UFF.

O material resultante da coleta dos dados sociodemográficos foi tabulado no software Microsoft Excel, versão 2007 e analisado no programa estatístico SPSS Statistics versão 22.

Os registros provenientes da observação participante foram analisados em vias de extrair das situações observadas, elementos que elucidassem a relação saúde e trabalho no contexto da produção de refeições coletivas.

Os resultados do presente estudo fazem parte do projeto aprovado pelo Comitê de Ética em Pesquisa da Escola Nacional de Saúde Pública Sergio Arouca, Parecer no 1.483.381, e da Universidade Federal Fluminense, Parecer no 1.605.857. No início da pesquisa, foi apresentado o Termo de Consentimento Livre e Esclarecido, no qual o pesquisado assentava a concordância em participar do estudo, após esclarecimentos quanto aos procedimentos a serem empregados, a garantia de sigilo das informações prestadas e a possibilidade de declinar a participação. 


\section{RESULTADOS}

\section{O perfil dos trabalhadores terceirizados no Restaurante Universitário da UFF}

Os trabalhadores terceirizados participantes da pesquisa trabalhavam sob o regime da CLT, perfazendo, pois, 44 horas semanais divididas de segunda a sexta-feira; eram distribuídos em dois turnos de trabalho para atender a produção das refeições almoço e jantar, e; pertenciam aos cargos de auxiliar de produção, cozinheiro, estoquista, encarregado de cozinha e restaurante, açougueiro e auxiliar de gestão, os quais eram contratados pela empresa $\mathrm{X}$ e, dos cargos de limpador e encarregado de limpeza, da empresa $\mathrm{Y}$, conforme Tabela 1.

Tabela 1. Distribuição dos trabalhadores terceirizados do RU-UFF por empresa e cargo. RU-UFF, 2016

\begin{tabular}{|c|c|c|c|}
\hline \multirow{2}{*}{ Prestadora de serviço } & \multirow{2}{*}{ Cargo } & \multicolumn{2}{|c|}{ Trabalhadores $(n=68)$} \\
\hline & & Frequência & Frequência \\
\hline \multirow{7}{*}{$\mathrm{X}$} & Açougueiro & 4 & 6,8 \\
\hline & Auxiliar de Gestão & 2 & 3,4 \\
\hline & Auxiliar de Produção & 36 & 61,0 \\
\hline & Cozinheiro & 3 & 5,1 \\
\hline & Encarregado de cozinha e restaurante & 8 & 13,6 \\
\hline & Estoquista & 6 & 10,2 \\
\hline & Total & 59 & 100,0 \\
\hline \multirow{3}{*}{ Y } & Encarregado de Limpeza & 1 & 11,1 \\
\hline & Limpador & 8 & 88,9 \\
\hline & Total & 9 & 100,0 \\
\hline
\end{tabular}

Fonte: Os autores, 2017

Nota: Tabela elaborada a partir de arquivos das empresas terceirizadas X e Y.

Entre os pesquisados identificou-se maior predominância do sexo masculino (63,23\%), sendo eles distribuídos em funções com intensa exigência de força física, sobretudo pelo transporte/manuseio de cargas pesadas, mas uma maioria de mulheres (44\%) exercendo seu trabalho na área de pré-preparo de Hortaliças e Distribuição de Refeições, cuja atividade na Distribuição, era, predominantemente, o porcionamento do prato proteico, relegando a elas o trabalho marcado pelo esforço repetitivo (Tabela 2).

Tabela 2. Distribuição dos trabalhadores terceirizados por Área da Atuação no RU-UFF e Sexo. Niterói, 2016

\begin{tabular}{|c|c|c|c|}
\hline \multirow{2}{*}{ Área de Atuação no RU-UFF } & \multicolumn{2}{|c|}{ Sexo } & \multirow{2}{*}{ Total } \\
\hline & Feminino & Masculino & \\
\hline Almoxarifado & 2 & 7 & 9 \\
\hline Cocção & 0 & 8 & 8 \\
\hline Distribuição de Refeições e Refeitório Externo & 1 & 0 & 1 \\
\hline Higienização de Utensílios - Pratos e Talheres & 0 & 3 & 3 \\
\hline Higienização de Utensílios - Panelas & 0 & 4 & 4 \\
\hline Limpeza Unidade Gragoatá & 4 & 1 & 5 \\
\hline Limpeza Unidade Gragoatá - Cozinha & 0 & 1 & 1 \\
\hline Limpeza Unidade Gragoatá - Refeitório 1 & 0 & 2 & 2 \\
\hline Limpeza Unidade Gragoatá - Refeitório 2 & 0 & 1 & 1 \\
\hline Pré-preparo de Carnes & 0 & 5 & 5 \\
\hline Pré-preparo de Hortaliças & 0 & 1 & 1 \\
\hline Pré-preparo de Hortaliças e Distribuição de Refeições (Porcionamento de Prato Proteico) & 11 & 0 & 11 \\
\hline Pré-preparo de Hortaliças e Distribuição de Refeições (Repositor) & 0 & 5 & 5 \\
\hline Pré-preparo de Hortaliças e Refeitório Externo & 7 & 5 & 12 \\
\hline Total & 25 & 43 & 68 \\
\hline
\end{tabular}

Fonte: Os autores, 2017.

Nota: Tabela elaborada a partir de arquivos das empresas terceirizadas X e Y. 
$\mathrm{Na}$ Tabela 3, conforme os dados sociodemográficos coletados, foi possível perceber a maior prevalência de trabalhadores moradores do município de São Gonçalo (64,7\%), com ensino médio completo $(38,2 \%)$, com idades entre 25 a 34 anos $(35,3 \%)$ e que recebiam até 1 salário mínimo e meio $(79,4 \%)$, sendo a remuneração máxima até 2 salários mínimos. Apesar do ensino médio completo ter sido a escolaridade predominante, mais da metade dos entrevistados tinha até o ensino médio incompleto $(54,5 \%)$, sendo o ensino fundamental incompleto a segunda escolaridade mais prevalente entre os terceirizados $(30,9 \%)$.

Tabela 3. Distribuição dos trabalhadores terceirizados do RU-UFF por Característica Sociodemográfica, 2016

\begin{tabular}{|c|c|c|}
\hline Característica Sociodemográfica & $\begin{array}{l}\text { Frequência } \\
\quad(n=68)\end{array}$ & Porcentagem \\
\hline \multicolumn{3}{|l|}{ Escolaridade } \\
\hline Ensino Fundamental Incompleto & 21 & 30,90 \\
\hline Ensino Fundamental Completo & 8 & 11,80 \\
\hline Ensino Médio Incompleto & 8 & 11,80 \\
\hline Ensino Médio Completo & 26 & 38,20 \\
\hline Ensino Superior Incompleto & 1 & 1,50 \\
\hline Ignorado & 4 & 5,90 \\
\hline \multicolumn{3}{|l|}{ Município de residência } \\
\hline Itaboraí & 1 & 1,50 \\
\hline Magé & 1 & 1,50 \\
\hline Maricá & 1 & 1,50 \\
\hline Niterói & 12 & 17,60 \\
\hline Rio de Janeiro & 3 & 4,40 \\
\hline São Gonçalo & 44 & 64,70 \\
\hline Ignorado & 6 & 8,80 \\
\hline \multicolumn{3}{|l|}{ Relação Salário/Salário Mínimo - SM (Referência 2016 - R\$880,00) } \\
\hline Até $1,5 \mathrm{SM}$ & 54 & 79,40 \\
\hline Maior que 1,5 até $2 \mathrm{SM}$ & 14 & 20,60 \\
\hline \multicolumn{3}{|l|}{ Faixa etária (em anos) } \\
\hline 20 a 24 & 5 & 7,35 \\
\hline 25 a 29 & 9 & 13,24 \\
\hline 30 a 34 & 15 & 22,06 \\
\hline 35 a 39 & 6 & 8,82 \\
\hline 40 a 44 & 2 & 2,94 \\
\hline 45 a 49 & 6 & 8,82 \\
\hline 50 a 54 & 7 & 10,29 \\
\hline 55 a 59 & 8 & 11,76 \\
\hline$>60$ & 4 & 5,88 \\
\hline Ignorada & 6 & 8,82 \\
\hline
\end{tabular}

Nota: Tabela elaborada a partir de arquivos das empresas terceirizadas X e Y.

A Tabela 4 apresenta e estratifica a condição salarial por sexo, denotando a diferença salarial entre gênero, em prejuízo do sexo feminino; ou seja, que para cada 2 homens recebendo de 1,5 s.m. a 2 s.m., havia apenas 1 mulher em igual patamar. 
Tabela 4. Distribuição dos trabalhadores terceirizados do RU-UFF por salário e sexo. RU-UFF, 2016

\begin{tabular}{c|c|c|c|c|c}
\hline Relação Salário/Salário Mínimo - SM & \multicolumn{4}{|c|}{ Sexo/Frequência } & \multirow{2}{*}{ Total } \\
\cline { 2 - 6 } (Referência 2016 - R\$880,00) & Feminino & \% & Masculino & \% & 76,7 \\
Até 1,5 & 21 & 84,0 & 33 & 54 \\
Maior que 1,5 até 2 & 4 & 16,0 & 10 & 23,3 & 14 \\
Total & 25 & 100,0 & 43 & 100,0 & 68 \\
\hline
\end{tabular}

Fonte: Os autores, 2017.

Nota: Tabela elaborada a partir de arquivos das empresas terceirizadas X e Y.

A partir dos dados das entrevistas, identificouse o tempo de serviço dos terceirizados no RU-UFF, bem como o número de empresas associadas a esse tempo. Mais da metade dos trabalhadores terceirizados tinham de 2 a 4 anos de trabalho no RU-UFF $(51,6 \%)$, tendo nesse período, quase a totalidade $(87,5 \%)$ passado por 3 empresas diferentes.

\section{O modo de organização do trabalho no Restaurante Universitário da UFF}

O RU-UFF produz diariamente cerca de 7.500 refeições, distribuídas entre almoço e jantar, preparadas em uma única Cozinha Industrial situada no campus do Gragoatá e distribuídas em dois refeitórios do mesmo campus e em mais quatro refeitórios, ditos Refeitórios Externos, localizados na Faculdade da Veterinária, no campus da Praia Vermelha, no Hospital Universitário Antônio Pedro e na Reitoria da Universidade.

O cardápio era composto de duas saladas, prato principal de origem animal, guarnição, acompanhamentos (arroz e feijão), sobremesa e refresco. Exceto por problemas operacionais, normalmente, o cardápio do almoço era o mesmo do jantar em todos os Refeitórios.

A distribuição das refeições ocorria de forma mista, na maioria dos Refeitórios, dado que as preparações acompanhamento (arroz e feijão), guarnição, saladas, sobremesa e refresco eram disponibilizados na modalidade autosserviço e, a preparação proteica, era distribuída por trabalhador do Restaurante em quantidade previamente estipulada.

O horário de almoço iniciava-se às $11: 30 \mathrm{~h}$ e finalizando às 14:30h, variando, conforme o refeitório, o horário de início e fim da oferta dessa refeição. $\mathrm{O}$ horário do jantar era de $17 \mathrm{~h}$ às $19 \mathrm{~h}$, sendo, esta refeição, no entanto, servida apenas nos campi Gragoatá e Praia
Vermelha, cujo horário, nesse último, às sextas-feiras alterava-se para de $17 \mathrm{~h}$ às $18 \mathrm{~h}$.

Para produção e distribuição das refeições, os trabalhadores dividiam-se, conforme cargo e áreas de atuação no RU-UFF (Tabela 2), para atender à demanda diária. Para isso, dispunham de utensílios e equipamentos específicos, que, no entanto, conforme relato dos pesquisados, sistematicamente apresentavam funcionamento irregular, tendo como causa a reposição tardia de utensílios danificados e a ausência de manutenção de rotina dos equipamentos.

Cabe destacar que parte dos trabalhadores pesquisados tinha sua carga horária diária distribuída entre a Cozinha Industrial e os Refeitórios Externos, o que resultava em redução do volume de trabalhadores durante o conjunto do processo produtivo. Isso significa dizer que apesar da quantidade de trabalhadores contratados, nem sempre a sua totalidade estava operando na produção de refeições.

A análise do tema organização do trabalho pela fala dos entrevistados revelou que, para a maioria dos cargos, a troca do empregador trazia alguma modificação na vida dos trabalhadores, pela possibilidade de aumentar ou diminuir o salário, de mudar de setor e, por conseguinte, mudar o processo de trabalho e as exigências quanto ao comportamento no trabalho.

Olha varia muito porque a vai, vai das exigências da direção que tá entrando nova, junto com a empresa, da supervisão que tá vindo fazer a cobransa. (E4)

[...] O importante mesmo é o salário, né?! Às vezes cai, às vezes sobe. (E14) 
Diante da pressão temporal para produção das refeições, próprio de UANs ${ }^{[2]}$, o longo período dedicado ao trajeto casa-trabalho foi outro elemento identificado em todos os cargos, tendo trabalhadores que passam até 4 horas de suas vidas nesse trajeto, dados o horário de entrada e saída do serviço (onde o engarrafamento é fator preponderante) e a moradia distante do trabalho (muitos moravam em cidades vizinhas a Niterói).

Apareceu nos cargos de auxiliar de gestão, estoquista e auxiliar de produção, além do supracitado, a ocorrência de jornada de trabalho flexível, seja por "passar do horário" ou "suprimir" tempo de descanso/almoço para atender às demandas de serviço.

A gente espera, espera, espera, espera, a gente passa do nosso horário... E a gente não, pô, e aqui também a gente não tem valor também, né, a gente espera, espera, espera, a gente far, far, far. e num, a gente não pede nem obrigado. A gente sai às vezes é um obrigado, às vezes até incentiva a gente também, né?! A gente passa do horário aí, epensa que é obrigação da gente passar do horário, não é obrigação da gente não. A gente fica porque tem que ficar. (E14)

Eu sou do corte, ai quando é onze, onze e meia eu saio, ai vou pra Veterinária servir... Ai sirvo, boto as farinhas, né, boto as mesas, farinha, guardanapo, boto, vinagre, essas coisas e limpo a rampa depois fecha lá duas horas, ai espero o carro e venho embora. Ai quando chega aqui, eu tô na hora de almoço, porque hoje eu não fiquei né, porque hoje, que, tinha tanta coisa que não dava (para tirar a hora de almoço) [...] (E11, inclusões dos autores)

A polivalência pôde ser identificada nas falas de trabalhadores de vários cargos, mascarada como opção daquele trabalhador "disposto a colaborar com o serviço", como ajuda aos colegas de trabalho de outro setor, como necessidade de cobrir faltas, como consequência da diminuição de funcionários no RUUFF, sendo necessário assumir várias tarefas para finalização do serviço.

Olha só, quanto, quais são as funções que nós temos aqui? Seria dificil eu dizer qual que eu não desempenho. [...] Eu, eu, chego, eu faço qualquer coisa, não adianta. (E1)
Quando eu chego eu vou pra bancada, ajudar a preparar, a fazer o pré-preparo dos alimentos. Até umas deze, dez horas. Ai quando termina a gente fica livre. Ai dá o horário pra gente montar as rampas do refeitório pro almoç, também, trabalho com repositor, e também quando falta o, [...] que é do suco eu também vou pra parte do suco, também. [...] (E31)

A sobrecarga foi o elemento da organização do trabalho mais constatado pela maioria dos trabalhadores independente do cargo, sendo colocada por eles como expressão da falta de funcionários (seja no quantitativo geral de trabalhadores do RU-UFF, seja pela não reposição do trabalhador faltante), como acúmulo de funções, como resultante de condições ruins de trabalho e/ou como muito trabalho para poucos.

Ah, eu acho que eu sou sobrecarregado porque não tem os materiais adequados, né?! (E5)

Porque, principalmente à noite, eu fico sozinho na cozinha e precisa ai de mais um pra me ajudar. Ai eu tenho que terminar depois aqui na cozinha e ir pra outro setor ter que ajudar lá. (E30)

$\mathrm{Na}$ análise do tema organização do trabalho por subárea de atuação na Cozinha, em dissonância com a polivalência, identificou-se também um trabalho monótono e repetitivo nas subáreas de pré-preparo de hortaliças e de Distribuição de Refeições, cuja força de trabalho era, predominantemente, feminina.

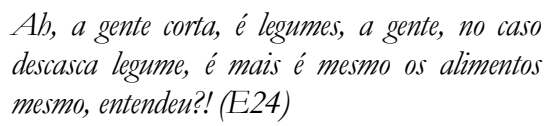
descasca legume, é mais é mesmo os alimentos mesmo, entendeu?! (E24)

É, limpar, servir, cortar. (E28)

A subárea de açougue não apareceu identificada como área em que a sobrecarga de trabalho estivesse presente. A subárea de estoque apareceu como a que mais submete os trabalhadores a jornada de trabalho flexível, cotidianamente pela dificuldade na entrega das mercadorias em horário previamente estipulado.

A área de limpeza também se apresentou como monótona e repetitiva, pois cabia aos seus trabalhadores unicamente limpar o ambiente de produção de refeições e os refeitórios. 
As análises por empresa e por tempo de serviço revelaram que os trabalhadores com mais tempo de RU-UFF e que menos vivenciaram a rotatividade de empregador eram da empresa $\mathrm{Y}$, cujos serviços prestados à Universidade datavam de alguns anos.

\section{Relação Saúde e Trabalho na produção de refeições coletivas no RU-UFF}

O ambiente de trabalho na Cozinha Industrial do RU-UFF, constituído de uma estrutura predial datada de 1986, com histórico de apenas uma reforma nas instalações elétricas e hidráulicas no ano 2000[22,23], apresentava condições desfavoráveis à saúde dos trabalhadores, a saber: ausência de sistema de exaustão adequado, propiciando acúmulo de vapores e temperatura elevada durante o processo produtivo; instalações com necessidades de reparo, como lâmpadas sem proteção contra quebra e explosão, pisos com risco de derrapagem seja pelo escoamento inadequado de água ou desgaste do material de revestimento; equipamentos sem manutenção preventiva e/ou corretiva conforme preconizado por legislação ${ }^{[24]}$.

A análise do tema relação saúde e trabalbo, por meio da fala dos entrevistados, revelou que a concepção de saúde mais recorrente nos cargos, exceto para os cargos de cozinheiro e auxiliar de gestão, foi saúde como condição necessária para trabalbar. Entretanto, algumas outras abordagens também apareceram, sobretudo, saúde é boa alimentação, mas também saúde é completo bem-estar físico e psíquico, é dormir bem, é estar livre de dor e doenças, é prevenção e cuidado, é rir, é cuidar dos outros.

Saúde pra mim é tudo, né?! Porque se a gente não tiver saúde como é que a gente vai trabalhar? Pelo amor de Deus. É o que eu peço a Deus todos os dias, que me dê muita saúde pra mim continuar, né?! Tem que trabalhar (E13)

[...] só de levantar e conseguir vim trabalhar já é uma saúde, entendeu?! Eu acho. (E24)

A relação saúde e trabalho apareceu, na análise por cargos, quase sempre e para a maioria deles, como uma relação prejudicial ou potencialmente prejudicial.
Esse sabão brabo que a gente mexe aí. Que se cair na mão, meu irmão, já descasca tudo. (E8)

[...] se você num tiver problema de coluna, aqui você vai adquirir. Se você não, se você não tiver tendinite, aqui você vai adquirir. Se você não tiver varize, aqui você vai adquirir, porque até então, vocêpassa maior parte do tempo, muito, eu mesmo sou uma, eu fico em pé da, da hora que eu chego até a hora que saio. [...] as pernas dói, joelho dói. Tudo dói [...]. O ombro, afeta o ombro, né, e muitas coisas, o peso que você pega dos pratos, dos talher, e não-sei-o-quê, e vai pra lá, pra cá, cuba pesadas, tudo isso, afeta bastante. (E15)

Interfere no emocional. Apesar de eu não me deixar me abater, por, por essa questão, mas interfere no emocional, entendeu?! [...] (E27)

Apesar disso, a relação saúde e trabalho também foi levantada como uma relação saudável para alguns trabalhadores dos cargos de Auxiliar de Produção e Limpador. A não relação saúde e trabalho também foi apontada, principalmente associada a uma postura individual de autocuidado, autocontrole, ou seja, como adoção de uma "conduta responsável com si mesmo".

Associado a relação negativa entre trabalho e saúde, foi relatado pela maioria dos entrevistados, independentemente do cargo, o conhecimento e/ou vivência de acidentes de trabalho no cotidiano da produção de refeições, relacionados a queimaduras, cortes, quedas, em que o afastamento do trabalho, por diversas vezes fora necessário.

Poucos foram os trabalhadores, independentemente do cargo, que atribuíram à terceirização, alguma interferência, seja positiva ou negativa em sua saúde, mas algumas falas apontaram para essa relação.

Ser servidor você tem um, um trabalho melhor, né, um salário melhor. Tem como você se cuidar mais, né?! (E14)

Com certeza. Ah, porque a carga de trabalho menor, né, é, assim, não tem um estresse não tem uma responsabilidade tão grande que deveria ter, mas não tem, entendeu, então... Não tem tanta preocupação, então saúde rende mais, né, fica mais estabilizada... (E26) 
Entretanto, entre os que não identificaram relação entre terceirização e saúde, houve relatos de associação entre terceirização e piores condições de trabalho.

[...] só, só o que muda assim, é, o cargo, o cargo, a carga horária que muda também, é, assim, o valor eles recebem um pouco mais, a gente recebe ma, menos, só isso, o resto, tá de boa, tá de boa. (E5)

Nas análises da relação saúde e trabalho por área de atuação, os trabalhadores da empresa Y não identificaram relação entre terceirização e saúde, nem terceirização e condições de trabalho, como apontado por alguns trabalhadores. Esses trabalhadores tinham a prerrogativa de quase não vivenciarem a rotatividade de empresas, o que possivelmente tornou secundária a questão da terceirização para sua saúde.

Nas análises por tempo de serviço e empresa, nenhum achado divergente dos supracitados foi identificado.

Pela observação participante, foi possível identificar inovações e/ou reforçar dados relevantes para temática saúde e trabalho já mencionados nas entrevistas, a saber: 1) condições de trabalho desconfortáveis, principalmente pelo desconforto térmico e risco de acidente de trabalho pelo defeito em equipamentos; 2) sobrecarga de trabalho, manifestada na relação conflituosa entre trabalhadores para atender à demanda de serviço; nos relatos de dores articulares em mãos e punhos, principalmente pelas trabalhadoras; no afastamento do trabalho devido às dores lombares por trabalhadores do sexo masculino; na conjunção das tarefas relacionadas à produção de refeições no RUUFF e outras demandas pelos trabalhadores da subárea do estoque seco; 3) escassez de treinamento em segurança no trabalho, foi observado que do conjunto de temas de treinamento ministrados aos trabalhadores, apenas havia a intenção da empresa X em executar treinamento sobre o tema durante o tempo da pesquisa e; 4) perfil de doenças por gênero, as queixas dos desconfortos/lesões divergiram entre os sexos: para as mulheres, lesões mais comuns do esforço repetitivo e para os homens, do manuseio/transporte de cargas pesadas.

\section{A terceirização e a Segurança Alimentar e Nutricional: a relação alimentação e trabalho no RU-UFF}

$\mathrm{Na}$ análise do tema relação alimentação e trabalho verificou-se que a concepção de alimentação saudável predominante na fala dos entrevistados, independentemente do cargo, foi àquela alimentação que faz bem para a saúde, que é equilibrada/balanceada, que tem todos os nutrientes que o corpo precisa, que deve ser com pouco sal, pouca gordura e deve ter legumes, verduras e frutas. Essa percepção, como disse um dos entrevistados, baseava-se na alimentação servida no RU-UFF.

Questionados sobre a relação do seu trabalho com uma alimentação saudável foi percebido, na análise por cargos, para a maioria, sendo unânime para os cargos de limpador e encarregado de limpeza, que seu trabalho lhe permitia uma alimentação saudável. Entretanto, alguns funcionários revelaram que seu trabalho não lhe permitia uma alimentação saudável, ou a permitia, às vezes.

Não. Não. Porque, é, no meu caso, no meu caso, tá?! Tô falando de mim, aí as coisas é muito corrida, é muito coisa, não consigo, por exemplo, ter horário pra almoçar. Não consigo ter horário pra descansar, que eu não descanso almoço, não, entendeu, deveria ter. (E1)

Olha, permite e não permite. Porque no caso quando se trata do trabalho tem vezes que às vezes tô trabalhando ainda, já passou o café da, da manhã, já passou o horário de almoço, não porque o pessoal é rígido com isso, mas o, a parte do café da manhã e o café da tarde, ás vezes a gente acaba abrindo mão porque a gente tá agarrado lá dentro dando conta do serviço, entendeu?! (E4)

Essas falas identificaram a dinâmica do trabalho, ou intensificação dessa, como o fator limitante para se alimentar, independentemente da alimentação ser ou não ser saudável.

A maioria dos trabalhadores, independentemente do cargo, identificou como positivo poder se alimentar no local de trabalho, dado que isso favorecia a sua saúde. Sendo apontado, por alguns trabalhadores, que isso os livrava da rotina diária da "marmita", como alternativa primária para sua alimentação no trabalho. 
Com certeza. Com todas as certezas. Imagina, é uma comida quentinha, né, fresquinha, mil vezes melhor do que uma marmita. Eu, pelo menos, acho. (E2)

É, muito melhor, cara, aqui é, eu, eu sinceramente, cara, e falando sério pra você, eu me alimento muito melhor aqui do que em casa. Pode ter certeza. (E18)

Sobre o questionamento se os trabalhadores ficavam sem se alimentar, por algum motivo, durante o expediente de trabalho, para os cargos de cozinheiro, limpador e encarregado de limpeza não existiram motivos para ficarem sem se alimentar durante sua jornada de trabalho. Nos outros cargos, apareceram as duas posições, sendo que os motivos mais recorrentes para o "sim" (ficar sem comer no trabalho) foram "não gostar da comida servida", ou "por necessidade do serviço". Esse último motivo coaduna com os achados anteriores, onde o modo de organização do trabalho é fator limitante para se alimentar adequadamente.

[...] às vezes eu não consigo ter tempo pra comer, entendeu, às vezes en fico duas, três horas às vezẹes quatro horas sem comer, cinco horas por causa da demanda de trabalho, entendeu?! (E6)

$\mathrm{Na}$ análise por área de atuação, os trabalhadores do setor de limpeza foram unânimes em mencionar que o trabalho permitiu uma alimentação saudável e que por nenhum motivo ficaram ou conheciam alguém que teria ficado sem se alimentar durante a jornada de trabalho.

Sobre o questionamento do salário mais os benefícios, incluindo o auxílio alimentação, ser suficiente para garantir uma alimentação saudável, os trabalhadores ficaram divididos. Praticamente metade disse que era suficiente, e a outra que não. Só para os cargos de cozinheiro e açougueiro foi consenso que o valor não era suficiente e para o de encarregado de limpeza, como suficiente. Sendo importante mencionar, que para alguns trabalhadores que consideraram suficiente, vários mencionaram que $\mathrm{o}$ valor do "vale compras" era muito baixo.

Vivendo desse modo não dá não. Porque o salário, no caso, já tá baixo, né [...] E, e vamo botar também que esse cartão alimentação que eles forneceram pra gente, eu aqui que é mais assim um "quebra-galho" porque o cartão de cento $e$ cinquenta reais acho que cento e cinquenta reais a gente não far. nem uma compra decente pra dentro de uma casa. No caso, eu, na minha casa somos três pessoas: eu, minha esposa e minha filha, mas não, não dá conta pro mês inteiro. (E4)

Não. Acredito que não porque o custo de vida lá fora boje tá muito grande, então, é, às vezes a gente deixa de comer uma coisa mais saudável porque você tem que comprar um outro tipo de coisa ou pagar uma prestação, on uma coisa [...]. (E21)

Não porque en gasto é muito, né, e o salário é pouco, então pra você ter uma alimentação saudável, você tem que trabalhar fora pra poder ajudar, né, no orçamento. (E29)

$\mathrm{Na}$ análise por empresa e por tempo de serviço não foram observadas singularidades ou inovações frente ao que já foi apresentado.

\section{DISCUSSÃO}

O perfil característico do trabalhador terceirizado no RU-UFF seria de um homem, jovem, morador de São Gonçalo, auxiliar de produção na empresa X, com ensino médio completo, remuneração de até 2 salários mínimos, cujo atributo marcante de seu processo de trabalho é o manuseio/transporte de cargas pesadas, com no máximo 4 anos de tempo de serviço no RU-UFF; porém, com uma média de 1 ano e 4 meses por empresa contratada, que divide o cotidiano da produção de refeições coletivas com os trabalhadores contratados diretamente pela Universidade, os servidores públicos. Características semelhantes a essas foram encontradas por outros autores $[15,16,23,25,26]$.

A coexistência, em um mesmo ambiente laboral, de trabalhadores empregados por diferentes empresas terceirizadas e sua convivência com os trabalhadores contratados diretamente pela UFF, os servidores públicos, implicava na fragmentação do coletivo de trabalho, na pulverização dos sindicatos de trabalhadores, e, por conseguinte, no enfraquecimento do poder de luta da classe trabalhadora frente as suas condições de trabalho, apontando para a precarização social do trabalho, própria do processo de terceirização, como já sinalizaram Druck ${ }^{[27]}$ e Alves ${ }^{[28]}$.

Destaca-se na empresa X certa "generalidade" dos cargos. A exceção dos cargos de cozinheiro, 
açougueiro e estoquista, cuja área de atuação no RUUFF, inevitavelmente, era cocção, pré-preparo de carnes e almoxarifado, respectivamente, os demais cargos poderiam atuar em qualquer fase do processo de produção de refeições. Fato este, identificado para a categoria profissional "Auxiliar de Produção".

Fato, que um auxiliar de produção pode atuar em qualquer fase do processo produtivo, mas $\mathrm{O}$ relevante a se elucidar é que os trabalhadores desse cargo "genérico" precisam se apresentar como detentores de várias habilidades e conhecimentos para a qualquer momento, a pedido do empregador, atuar em quaisquer das áreas de produção. Essa polivalência no trabalho já fora apontada por vários autores como uma das características do trabalho flexível[27,29-31].

O baixo salário pago a força de trabalho em condição de terceirização; a residência em municípios vizinhos ao local de trabalho, onde o custo de vida é mais acessível; o padrão de idade e escolaridade típico de um brasileiro ocupado, conforme critérios do IBGE; são características identificadas por outros estudiosos no contexto da precarização do trabalho[15,26-28,32].

Além dos baixos salários, a terceirização na esfera pública, marca-se pela rotatividade de empresas e manutenção do trabalhador, que aparentemente preservado, sujeita-se ao trabalho quase ininterrupto, posto que, mudando a empresa, o trabalhador precisa completar um ano de serviços prestados ao novo empregador para gozar de suas férias. Essas, por sua vez, embora constituam um direito trabalhista assegurado, deixam de ser desfrutadas pelo trabalhador, em prol da manutenção de seu emprego[26].

A terceirização ainda amarra os trabalhadores num ciclo sem fim, de baixa qualificação, com baixos salários [26], pois mesmo a "promoção", que possibilita aumento de salário é inconstante e momentânea. Isso dificulta o planejamento da vida dos trabalhadores no longo prazo, sobretudo para investirem em sua qualificação, dado que essa "condição favorável" pode ser interrompida a qualquer momento.

A organização do trabalho no RU-UFF diante dos elementos apresentados nesse estudo representa uma transição incompleta do modo de organização fordista para o toyotista, já apontado por Colares ${ }^{[22]} \mathrm{em}$ estudo no RU-UFF. Isso, porque o trabalho nessa UAN combina características do fordismo como bierarquia, trabalho repetitivo, trabalho parcelar, e até certa "estabilidade" do empregado, dado o tempo de serviço de alguns terceirizados no RU-UFF, ao mesmo tempo, que apresenta trabalhadores com jornada de trabalbo flexivel, polivalência, encurtamento do tempo de vida/tempo de trabalho, características comuns ao modo toyotista de organizar o trabalho[27,29,30,31].

Importante destacar do processo de trabalho no RU-UFF, a divisão sexual do trabalho, atribuindo ao sexo feminino, funções mais relacionadas às "características femininas" (paciência, minúcia, atenção, entre outras) em contraposição às "características masculinas" (força física, lógica, aptidão para o comando, etc.), bem como a um padrão de doenças que se distingue pelo posto, mas, sobretudo pelo sexo ${ }^{[33,34]}$.

Ainda como parte desse contexto, cabe mencionar o valor pago a força de trabalho feminina na sociedade capitalista. No caso da UAN analisada, não pelas mulheres receberem salários mais baixos que os homens no desempenho das mesmas atribuições, mas por se concentrarem em cargos com piores remunerações. Ademais, apontam para o fato de grupos historicamente mais vulneráveis, em que se incluem as mulheres, sofrerem, de forma ainda mais perversa, a precarização do trabalho[ ${ }^{[33,35]}$.

Castro \& Maffia[ ${ }^{[36]}$ reforçam esses achados: em estudo sobre gênero em cozinhas profissionais, revelaram que a diminuta ocupação de cargos de maior prestígio/remuneração pelas mulheres, se comparada aos homens, é reflexo da divisão sexual do trabalho nesse ambiente laboral.

A precarização do mundo do trabalho contempla ainda piores condições de trabalho, que neste estudo apareceu pelo desajuste de instrumentos e equipamentos, acarretando intensificação do trabalho, dada a pressão temporal imposta para dar conta da produção de refeições ${ }^{[37]}$.

As manutenções predial e de equipamentos em UAN, sobretudo a preventiva, são essenciais ao processo produtivo, tanto para segurança dos trabalhadores como do produto final. Porém, desde que o poder público federal, na década de 90 , no contexto político de Estado Mínimo, extinguiu esse custeio para as IFES, ano a ano, o RU-UFF e seus trabalhadores tem experimentado alguma precarização das condições de 
trabalho pelo sucateamento de seus equipamentos e

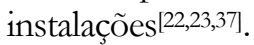

O encurtamento tempo de vida/tempo de trabalho ou precarização do homem-que-trabalha, apareceu nesse estudo também pelo longo trajeto casa/trabalho feito pelos entrevistados. Considerando um tempo médio de trajeto correspondente à $2 \mathrm{~h}$ e $50 \mathrm{~min}$, jornada de 9 horas de trabalho, sendo 1 hora de almoço, o tempo total dedicado ao trabalho é de $11 \mathrm{~h}$ e $50 \mathrm{~min}$, ou seja, quase metade do dia destina-se ao trabalho. Se considerarmos que são necessárias 8 h de sono por dia, resta ao trabalhador 4 horas para viver.

A vida pessoal reduzida ao trabalho assalariado foi apontada por Alves ${ }^{[2]}$ como uma das características da precarização do trabalho em tempos de restruturação produtiva. De certo, que esse elemento não configura exclusividade dos trabalhadores terceirizados do RU-UFF, senão uma imposição do capital à classe trabalhadora na atualidade, mas contribuem para considerar a precarização desse trabalho.

Sobre os desdobramentos dessa organização do trabalho na saúde dos trabalhadores, um primeiro destaque seria a concepção de saúde entre os pesquisados.

A associação de saúde com boa alimentação emergiu possivelmente desses trabalhadores ouvirem cotidianamente, na produção de refeições, a importância da alimentação para a saúde. Do contato direto com profissionais nutricionistas, estagiários de nutrição, e, por conseguinte, com suas concepções sobre a relação positiva entre saúde e alimentação adequada e saudável. Essa perspectiva de saúde aliada as variações do que é saúde para os trabalhadores entrevistados ensejam a presença de um conceito ampliado de saúde, que supera a concepção biologicista de ausência de doenças e insere-se na perspectiva de desfrute pleno da vida.

Por outro lado, a associação, recorrente, de saúde com capacidade produtiva, sedimenta a condição precária da classe trabalhadora na sociedade capitalista, identificada por Marx ${ }^{[38]}$, ou seja, desprovida de tudo, só lhe resta sua força de trabalho para sobreviver. E, o trabalhador enquanto mercadoria nessa sociedade deve ser de "boa qualidade", para ser passível de compra no mercado. Essa associação também poderia ser decorrente do que Alves ${ }^{[28]}$ chamou de precarização do homem-que-trabalha, pois sua vida passa a ser o seu trabalho, logo ter saúde para viver, é ter saúde para trabalhar.

Pelas falas dos entrevistados poderia se inferir que o processo de produção de refeições sujeita os trabalhadores a diversos problemas de saúde de ordem física (problemas de coluna, tendinite, dentre outros) e psíquica (como estresse, problemas emocionais), além do risco de dano à saúde pelo manuseio de produtos corrosivos e significativa probabilidade de acidentes de trabalho. Mas também, embora de maneira incipiente, alguns trabalhadores já associaram a terceirização a maior vulnerabilidade no trabalho. Resultados semelhantes foram mencionados por outros estudiosos da precarização do trabalho na contemporaneidade ${ }^{[25,27]}$ e do trabalho em cozinhas industriais ${ }^{[37,39]}$.

O trabalho na UAN em estudo, inserido no contexto da terceirização na esfera pública, apresenta riscos potenciais à saúde dos trabalhadores, mas também singularidades para a alimentação praticada pelos trabalhadores terceirizados.

A concepção de alimentação saudável presente na fala dos entrevistados determina e é determinada pelo seu processo de trabalho, assim como a adoção dessa alimentação é estimulada pela inserção desse trabalhador em uma Unidade de Alimentação e Nutrição de uma Instituição Pública Federal de Ensino, que por definição, fornece uma alimentação saudável, elaborada por nutricionistas, e adequada para a população adulta saudável, conforme recomendações do Ministério da Saúde. Essa afirmativa pode ser vislumbrada frente à maioria dos entrevistados relatarem os benefícios de se alimentar das refeições que produzem no seu trabalho.

Apesar disso, a dinâmica de trabalho foi apontada como um dos entraves para que a alimentação saudável fosse diariamente usufruída, de forma satisfatória, pelos trabalhadores terceirizados. Esse primeiro ponto de descontinuidade no acesso a alimentação saudável, imposta pelo trabalho, submeteriam esses trabalhadores a uma condição de Insegurança Alimentar e Nutricional (INSAN) durante o seu trabalho pela violação do atributo estabilidade no acesso. Uma pesquisa sobre as condições de (In)SAN de trabalhadores da cana-de-açúcar, também demonstrou que a intensa demanda de trabalho tornou 
irregular ou mesmo extinto o horário destinado à realização das refeições ${ }^{[17]}$.

Mas também, a UAN de análise funciona dentro de uma IFES, cujo funcionamento é interrompido pelo menos duas vezes no ano por recessos escolares e sempre que ocorre greve dos servidores públicos, e que, nesse contexto, salvo nos casos de férias, os trabalhadores terceirizados devem continuam a trabalhar para a Universidade, conforme contrato de prestação de serviço, sendo a alimentação dos trabalhadores terceirizados obrigação da empresa contratada. Isso significa dizer, que a benesse de acessar uma alimentação saudável no trabalho é sazonal, descontínua.

Porém, os trabalhadores das empresas X e Y recebem vale alimentação, cujos valores se definem pela Convenção Coletiva de Trabalho (CCT) dos Sindicatos que os representam, sugerindo que na ausência de funcionamento do RU-UFF, eles acessariam uma alimentação saudável via esse benefício mais o seu salário. Mas, como relatado nas falas dos entrevistados, em especial dos trabalhadores que recebiam $\mathrm{R} \$ 154,00$ de auxilio, a baixa remuneração não lhes permitia acessar o padrão esperado para uma alimentação saudável.

Essa fala dos entrevistados pode ser mais bem contextualizada quando se verifica que a empresa $\mathrm{X}$ forneceu, em 2016, o valor mensal de $\mathrm{R} \$ 154,00$ do benefício alimentação e a empresa $\mathrm{Y}, \mathrm{R} \$ 330,00$. Sob esse aspecto monetário, ainda que tais valores sejam suficientes para aquisição de alimentos para uma refeição principal, conforme necessidades de um trabalhador em idade adulta nos parâmetros estabelecidos pelo PAT, torna-se importante frisar que, quanto maior a renda, mais possibilidades de adoção de uma alimentação saudável[18] e, nesse caso, os trabalhadores da empresa X estariam em desvantagem.

Também se destaca que, na prática, os alimentos adquiridos pelo vale-alimentação podem ainda ser compartilhados com a família, conforme percebido na fala de alguns entrevistados, o que implica dizer que dificilmente o valor de $\mathrm{R} \$ 154,00$ atenderá as necessidades nutricionais de uma refeição principal para um trabalhador adulto durante todo o mês.

Ademais, considerando que o gasto mensal médio da cesta básica de alimentos ${ }^{4}$ por pessoa na cidade do Rio de Janeiro em 2016 foi de $\mathrm{R} \$ 444,41$, com o mês de outubro registrando o maior custo do período ( $\mathrm{R} \$ 456,44)$, o trabalhador precisaria de $\mathrm{R} \$ 1.369,32$ no mês de outubro de 2016 para prover alimentação para si e sua familia ${ }^{[40]}$. Nesse contexto, como a maioria dos trabalhadores deste estudo recebe até $1.5 \mathrm{~s}$. m., o valor do benefício alimentação torna-se uma contribuição significativa para lhes possibilitar acesso à cesta básica de alimentos. Desse modo, reforça-se que o valor do benefício alimentação pago aos pesquisados mostra-se insuficiente para prover uma alimentação saudável e adequada, sobretudo aos trabalhadores da empresa X.

É pertinente pontuar também, nesse caso, um efeito da terceirização: a fragmentação do coletivo de trabalhadores, pois a divergência de valores pagos pelas empresas, para um mesmo benefício, enfraquece uma luta conjunta desse coletivo em busca do aumento no valor destinado à sua alimentação, dificultando, pois, conquistas trabalhistas em prol do DHAA[27,28].

Os trabalhadores da empresa $\mathrm{X}$ continuam em desvantagem quando a CCT, que os rege, permite que o empregador suspenda por completo a concessão do benefício alimentação (denominando "vale-compras" pela CCT) quando houver falta injustificada ${ }^{[12]}$. Destaca-se que essa conduta fere as normativas do PAT, posto que, em caso de falta, o valor descontado do vale-alimentação deveria ser diretamente proporcional aos dias não trabalhados.

Pelas Convenções Coletivas de Trabalho, em que se vinculam os trabalhadores dessa pesquisa, a concessão do benefício alimentação não é obrigatória caso o local de prestação do serviço forneça alimentação aos seus empregados. Essa possibilidade soa como vantagem apenas para as empresas, posto que os trabalhadores tornam-se reféns da quantidade e da qualidade da alimentação disponível em seu local de trabalho. O direito à alimentação adequada e saudável se transverte em acesso à alimentação para garantia, única e exclusiva, de combustível para o trabalho.

4 A cesta básica de alimentos nacional é composta por 13 itens, cujas quantidades foram determinadas para atender às necessidades nutricionais de um trabalhador adulto no período de um mês ${ }^{[40]}$. 
Resgatando os atributos do DHHA, o conceito de segurança alimentar e nutricional, e as associações negativas entre trabalho (sua dinâmica e remuneração) e alimentação reveladas neste estudo, poderia se revelar uma condição de INSAN dos trabalhadores dessa pesquisa, sobretudo daqueles contratados pela empresa X. Dado que, o atributo acessivelé violado quando os terceirizados não percebem salários e benefícios que lhes permitam acessar alimentos saudáveis; bem como, ocorre violação do atributo estabilidade, quando os trabalhadores da empresa $\mathrm{X}$ podem ter suspenso o seu benefício alimentação, caso se ausente do trabalho sem justificativa, ou quando são obrigados a arcar com sua alimentação, mas a de sua família, dispondo de baixa remuneração e baixo auxílio alimentação.

\section{CONCLUSÕES}

A SAN é uma importante estratégia para garantia do Direito Humano a Alimentação Adequada e, no Brasil, assegurá-la a grupos mais vulneráveis socialmente ainda é um desafio, que, como podemos perceber ao longo dessa dissertação, encontra barreiras postas pelas mudanças no atual mundo do trabalho, sobretudo para os trabalhadores submetidos ao processo de terceirização.

Ao analisarmos a SAN de trabalhadores terceirizados em Restaurantes Universitários a partir da categoria trabalho, podemos constatar, que o modo de organização do trabalho em Unidades de Alimentação e Nutrição apresenta características que dificultam a adoção de uma alimentação saudável dentro e fora do trabalho.

A intensificação do ritmo de trabalho dada pela polivalência, jornadas de trabalho flexível, a fragmentação do coletivo de trabalhadores, marcas de um modo de organização forjado no contexto da reestruturação produtiva e sabidamente promotor de precarização do trabalho, tornam-se elementos que dificultam a adoção de uma alimentação, sobretudo saudável, no processo de produção de refeições coletivas.

Não podemos negar que o processo de produção de refeições guarda uma dinâmica extenuante, dada à exigência de transporte de cargas pesadas, intensa produção de ruídos pelo funcionamento do maquinário, trabalho repetitivo, calor excessivo e riscos de acidente de trabalho pelo manejo de equipamentos, utensílios e produtos de limpeza, o que já engendra um conjunto potencial de problemas à saúde. Mas, o processo de privatização das IFES, com consequente terceirização da força de trabalho nos restaurantes universitários, como apontada neste estudo, faz exacerbar essas condições, potencializando e inovando nos riscos à saúde dos trabalhadores.

Além das conhecidas formas de precarização engendradas pela terceirização, ela viola, no caso dos trabalhadores em UAN, o direito à alimentação, sabidamente importante para a garantia da saúde dos trabalhadores de baixa renda. Como mostrado nessa pesquisa, o benefício alimentação é baixo e pode ser inclusive suprimido como punição ao trabalhador. Além disso, a aparente vantagem dos trabalhadores pesquisados, se comparados aos terceirizados que precisam levar "marmita" para o trabalho, dado as chances de alimentação provinda desse meio ser altamente precária, relativiza-se, frente ao fato desses trabalhadores não terem a alimentação no trabalho como uma constante, posto que em casos de interrupção no funcionamento do RU-UFF, resta-lhes arcar com sua alimentação com seus baixos salários e benefícios.

A terceirização da força de trabalho no RUUFF nas condições apresentados volta a tratar a alimentação, praticamente, para garantir a produtividade no trabalho. Se há produção de refeições no RU-UFF há possibilidade, ao menos, de acessar uma alimentação saudável, mas, aliado a isso, um conjunto de riscos e potenciais riscos à saúde estão postos durante o cotidiano desse processo de trabalho. Para completar a concepção de alimentação para produtividade, caso o trabalhador da empresa $\mathrm{X}$ falte, sem justificativa, ao trabalho, ele pode perder o valealimentação do mês. A exploração da força de trabalho assume patamares impensáveis na ordem capitalista contemporânea.

\section{REFERÊNCIAS}

[1] UNFPA. Fundo de População das Nações Unidas. População Mundial [Internet]. 2011 [acesso em 18 out 2011]. Disponível em: http://www.unfpa.org.br/novo/index.php/populacao

[2] IFPRI. International Food Policy Research Institute. Welthungerhilfe; Concern Worldwide. Global Hunger Index - The 
challenge of hidden hunger [Internet]. 2014 [acesso em 15 out 2014]. Disponível em: http://www.ipaf.ufv.br

[3] BBC. Mais pessoas morrem por obesidade do que de fome no mundo, diz estudo [Internet]. 2012 [acesso em 14 dez 2012. Disponível em: http://www.bbc.com/portuguese

[4] Brasil. Lei no 11.346, de 15 de setembro de 2006. Cria o Sistema Nacional de Segurança Alimentar e Nutricional - SISAN. Diário Oficial da União. 18 set 2006.

[5] Burity V, Franceschini T, Valente F. Direito Humano à Alimentação Adequada no contexto da segurança alimentar e nutricional. Brasilia, DF: ABRANDH; 2010.

[6] FAO. Organização das Nações Unidas para a Alimentação e a Agricultura. O Estado da Segurança Alimentar e Nutricional no Brasil: Um retrato multidimensional. Relatório 2014. Brasília: FAO; 2014.

[7] DATASUS. Estatísticas Vitais. Sistema de Informações sobre Mortalidade - SIM. Mortalidade Geral: Brasil, óbitos por residência e categoria IV do CID 10 - Doenças endócrinas nutricionais e metabólicas no período de 2004 a 2014 [Internet]. 2015 [acesso em 09 mai 2015]. Disponível em http://tabnet.datasus.gov.br

[8] Maluf RS, Menezes F, Valente FL. Contribuição ao Tema da Segurança Alimentar no Brasil. Cadernos de Debate. 1996;4:66-88.

[9] Brasil. Câmara Interministerial de Segurança Alimentar e Nutricional. Plano Nacional de Segurança Alimentar e Nutricional: 2016/2019. Brasília, DF: CAISAN, 2016.

[10] Brasil. Portaria Interministerial no 66, de 25 de agosto de 2006. Altera os parâmetros nutricionais do Programa de Alimentação do Trabalhador - PAT. Diário Oficial da União. 28 ago 2006.

[11] DIEESE. Proposta de Reformulação do Programa de Alimentação do Trabalhador. Relatório Final sobre o Programa de Alimentação do Trabalhador (PAT). São Paulo: DIEESE; 2013.

[12] ABERC. Associação Brasileira das Empresas de Refeições Coletivas [Internet]. 2015 [acesso em 14 nov 2015]. Disponível em: http://www.aberc.com.br

[13] Queiroz PWV; Coelho AB. Alimentação Fora de Casa: uma análise do consumo brasileiro com dados da POF 2008-2009. In: Anais do Encontro ANPEC [Internet]; 2015; Florianópolis. Florianópolis: ANPEC; 2015 [acesso em 15 set 2016]. Disponível em: https://www.anpec.org.br

[14] DIEESE. O Processo de Terceirização e seus efeitos sobre os trabalhadores no Brasil. Sistema de Acompanhamento de Contratações Coletivas - SACC-DIEESE. São Paulo: DIEESE; 2003.
[15] Andreta RL, Campos RS. Base da pirâmide social brasileira? O perfil dos Trabalhadores terceirizados no contexto dos anos 2000. Revista da ABET. 2015;14(2):241-158.

[16] Lourenço EAS. Terceirização: a destruição de direitos e a destruição da saúde dos trabalhadores. Serv. Soc. Soc. 2015;123:447475 .

[17] Verginio CJ. Trabalhadores empregados na colheita da cana-deaçúcar: uma análise da condição de Segurança Alimentar [dissertação]. Araraquara: Centro Universitário de Araraquara; 2011.

[18] Instituto Brasileiro de Geografia e Estatísticas (IBGE). Pesquisa de orçamentos familiares 2008-2009: análise do consumo alimentar pessoal no Brasil. Rio de Janeiro: IBGE; 2011.

[19] Araújo MPN, Costa-Souza J, Trad LAB. A alimentação do trabalhador no Brasil: um resgate da produção científica nacional. Hist. Ciênc. Saúde-Manguinhos. 2010;17(4):975-992.

[20] Duarte R. Pesquisa qualitativa: reflexões sobre o trabalho de campo. Cad. Pesquisa. 2002;115:39-154.

[21] Forte M. O uso de questionários em trabalhos científicos [Internet]. 2007 [acesso em 10 mai 2015]. Disponível em: http://telemedicina.unifesp.br

[22] Colares LGT. Processo de trabalho, saúde e qualidade de vida no trabalho em uma unidade de alimentação e nutrição: uma abordagem qualitativa [tese]. Rio de Janeiro: Escola Nacional de Saúde Pública Sergio Arouca; 2005.

[23] Jardim MFB. Análise do Trabalho em uma Unidade de Alimentação e Nutrição do Tipo Autogestão: um estudo de caso [dissertação]. Niterói: Universidade Federal Fluminense; 2005.

[24] Universidade Federal Fluminense. Manual de Boas Práticas do Restaurante Universitário da UFF. Rio de Janeiro: UFF; 2016.

[25] DIEESE/CUT. Terceirização e desenvolvimento: uma conta que não fecha - dossiê sobre o impacto da terceirização sobre os trabalhadores e propostas para garantir a igualdade de direitos. Subseção do DIEESE/CUT Nacional, Secretaria de Relações do Trabalho da CUT, Secretaria de Saúde da CUT. São Paulo: Central Única dos Trabalhadores; 2011.

[26] Carvalho LV, Bridi MA. Terceirização e Desigualdade: a terceirização e seus efeitos sobre os trabalhadores. Revista da ABET. 2015;14(1):99-113.

[27] Druck G. Unrestrained outsourcing in Brazil: more precarization and health risks for workers. Cad. Saúde Pública. 2016;32(6):e00146315.

[28] Alves G. Dimensões da Precarização do Trabalho: Ensaios de sociologia do Trabalho. Bauru: Canal 6; 2013. 
[29] Minayo-Gomez C, Thedim-Costa SMF. A construção do campo da saúde do trabalhador: percurso e dilemas. Cad. Saúde Pública. 1997;13(supl. 2):S21-S32.

[30] Alves G. Dimensões da Reestruturação Produtiva: ensaios de sociologia do trabalho. 2.ed. Londrina: Praxis; 2007.

[31] Netto JP, Braz M. Economia política: uma introdução crítica. 6.ed. São Paulo: Cortez; 2010.

[32] Instituto Brasileiro de Geografia e Estatísticas (IBGE). Pesquisa Nacional por Amostra de Domicílios Contínua, 2013 [Internet]. 2013 [acesso em 25 mai 2015]. Disponível em: http://www.ibge.gov.br/home/estatistica/indicadores/trabalhoere ndimento/pnad_continua/analise04.shtm

[33] Nancistanski N. Divisão sexual do trabalho: a sua constante reprodução. Paper. In: I Ciclo de Debates em Economia Industrial, Trabalho e Tecnologia, São Paulo. São Paulo: PUC-SP; 2003.

[34] Cartolo CM, Gomes AG. Geração de Renda para Mulheres e Divisão Sexual do Trabalho: Estratégias para o trabalho Feminino e a conquista da autonomia econômica no contexto da reestruturação produtiva. In: Anais do IV Congresso Paranaense de Assistentes Sociais. Curitiba: IV Congresso Paranaense de Assistentes Sociais; 2012.

[35] Braga RA. Política do Precariado: do populismo à hegemonia lulista. São Paulo: Boitempo; 2012.

[36] Castro MR, Maffia LN. Gênero na Cozinha Profissional. In: XXXVI Encontro da Associação Nacional de Pós-Graduação e Pesquisa em Administração). Rio de Janeiro: ANPGP; 2012.

[37] Colares LGT, Freitas CM. Processo de trabalho e saúde de trabalhadores de uma unidade de alimentação e nutrição: entre a prescrição e o real do trabalho. Cad. Saúde Pública. 2007;23(12):3011-3020.

[38] Marx K. Processo de Trabalho e Processo de Valorização. In: Marx K. O Capital: Crítica da Economia Política. 2.ed.. São Paulo: Nova Cultural; 1985. p. 149-164.

[39] Aguiar OB, Valente JG, Fonseca MJM. Descrição Sociodemográfica, laboral e de saúde dos trabalhadores do setor de serviços de alimentação dos restaurantes populares do estado do Rio de Janeiro. Rev. Nutr. 2010;23(6):969-982.

[40] DIEESE. Valor da Cesta Básica aumenta em todas as capitais em 2016: nota à imprensa [Internet]. 2017 [acesso em 04 jan 2017]. Disponível em: https://www.dieese.org.br 